\title{
Sunstein, Cass R.: Behavioral Science and Public Policy Sunstein, Cass R.: Behavioral Science and Public Policy
}

\author{
Guillermo Kreiman \\ Universidad de Oxford (Reino Unido) \\ ORCID: https://orcid.org/0000-0002-0083-8968 \\ guillermo.kreiman@politics.ox.ac.uk
}

\begin{abstract}
NOTA BIOGRÁFICA
Graduado en Derecho por la Universidad Autónoma de Madrid (2016) y Máster en Ciencias Sociales por el Instituto Carlos III-Juan March (2018). Actualmente realiza su doctorado en el Departamento de Ciencias Políticas y Relaciones Internacionales de la Universidad de Oxford. Su investigación multidisciplinar se centra en el análisis de procesos de polarización política, conflictos armados, política latinoamericana y filosofía política.
\end{abstract}

\section{RESUMEN}

Recensión del libro de Sunstein, Cass R.: Behavioral Science and Public Policy. Elements in Public Economics. Cambridge University Press, 2020.

\section{PALABRAS CLAVE}

Nudges; políticas públicas; ciencia del comportamiento.

\author{
ABSTRACT \\ Review of the book: Sunstein, Cass R.: Behavioral Science and Public Policy. Elements in Public \\ Economics. Cambridge University Press, 2020.
}

\section{KEYWORDS}

Nudges; public policies; behavioral science.

Incluso sin darnos cuenta de ello, nuestro día a día está marcado por numerosas intervenciones cuyo principal objetivo es afectar de manera directa o indirecta nuestro comportamiento ¿Quién no ha visto las impactantes imágenes que se incluyen en los paquetes de tabaco? ¿O el número de calorías y tipos de nutrientes en las etiquetas de los alimentos? Tampoco sorprende ya a ningún joven que renueve el abono de transporte ver la información sobre el descenso en la emisión de CO2 por la utilización del transporte público o usar el GPS del móvil para poder llegar al destino deseado. La pandemia provocada por la COVID-19 no ha hecho más que reforzar el uso de este tipo de recursos para disminuir la capacidad de transmisión del virus: acceso a puntos de distribución de gel hidroalcohólico, marcas de distanciamiento social, así como recomendaciones para el uso de mascarillas.

El nuevo libro de Cass Robert Sunstein, Behavioral Science and Public Policy, es una magnífica introducción para todos aquellos que busquen conocer las premisas básicas que subyacen a este tipo de intervenciones. El libro de Sunstein aborda de manera sucinta pero rigurosa los principales hallazgos en áreas tan diversas como la psicología cognitiva, la psicología social y la economía del comportamiento, analizando 
GAPP. Nueva Época - N. 25, marzo 2021 - ISSN: 1989-8991 - DOI: https://doi.org/10.24965/gapp.i25.10904 - [Págs. 87-90] Número monográfico - Los nudges y el diseño conductual de políticas públicas

Sunstein, Cass R.: Behavioral Science and Public Policy

Guillermo Kreiman

cómo todo este conjunto de evidencia puede tener un impacto directo en la mejora del bienestar humano a través de políticas públicas.

Desde un punto de vista analítico, el libro se centra principalmente en las implicaciones tanto filosóficas como prácticas de una categoría concreta del conjunto de herramientas disponibles para influir en el comportamiento de las personas: los cada vez más famosos nudges. A diferencia de otras intervenciones más coercitivas, como puede ser el caso de los mandatos y las prohibiciones, un nudge puede ser definido como «una iniciativa que afecta el comportamiento de la gente sin imponer ninguna carga material ni ofreciendo beneficios materiales significativos» (pág. 6) ${ }^{1}$. Dicho de otra forma, un nudge es «una intervención, proveniente de instituciones públicas o privadas, que afecta el comportamiento de la gente manteniendo su libertad de elección» (pág. 4).

Durante los últimos años, tanto la aplicación como el estudio sistemático de los nudges ha ganado en prominencia, en especial tras la publicación en 2009 del libro Nudge: Improving Decisions about Health, Wealth, and Happiness, firmado por el mismo Cass Sunstein y el premio Nobel de Economía Richard Thaler. Desde entonces, el debate académico se ha enriquecido considerablemente. Pero la cuestión de los nudges no solo se ha quedado en sesudos y abstractos debates académicos, sino que numerosos gobiernos e instituciones han decidido hacer uso de esta profunda evidencia para aplicarla a políticas públicas concretas. El Reino Unido, bajo el gobierno de David Cameron, fue uno de los pioneros con el establecimiento del «Behavioral Insights Team» [Equipo para el Conocimiento del Comportamiento]. Otros países como Australia, Alemania, Holanda, India o Qatar han establecido organismos de carácter similar en sus gobiernos. El mismo Cass Sunstein trabajó como asesor de la Casa Blanca en la época de la presidencia de Barack Obama con objetivos similares. Esta simbiosis entre conocimiento científico e instituciones públicas es un ejemplo fantástico de cómo la ciencia es capaz de promover e informar políticas públicas basadas en evidencia, lo que mejoraría significativamente el estándar de calidad de las mismas.

El libro de Sunstein está dividido en tres partes. Una primera, donde se exponen los fundamentos básicos de los nudges. Una segunda parte, en la que el elemento principal es la descripción de los principales descubrimientos en materia de ciencia del comportamiento durante los últimos años. Y por último, la tercera parte finaliza con un profundo análisis de las implicaciones filosóficas. En lo que resta de reseña me centraré principalmente en las dos últimas partes del libro.

Como he comentado anteriormente, decenas de políticas públicas han comenzado a estar directamente influenciadas por los nuevos descubrimientos en materia de ciencias del comportamiento. Una de las principales aportaciones de esta área de investigación es la puesta en cuestión de uno de los axiomas más básicos sobre la naturaleza humana defendidos por las teorías de la elección racional. El fundamento de estas teorías es que el ser humano tiene como principal objetivo la maximización de su beneficio (en nuestro caso, bienestar) y, por tanto, existirá una adecuación total entre sus actos y la búsqueda de este objetivo. A pesar de que las teorías de la elección racional siguen siendo fundamentales y de uso constante en una enorme variedad de áreas de las ciencias sociales, los avances en materia de ciencias del comportamiento ponen en cuestión las premisas básicas de los racionalistas: ¿realmente el ser humano maximiza sus preferencias cuando toma decisiones? La respuesta inequívoca para la ciencia del comportamiento es que, en algunas ocasiones, no. Por tanto, argumentan que el individualismo metodológico propuesto por las teorías de acción racional sufre de numerosos problemas, ya que existe una amplia evidencia que demuestra que los seres humanos no siempre tomamos las decisiones que maximizan nuestro beneficio. ¿Y por qué? Por dos factores principalmente: falta de información y sesgos de comportamiento.

En el libro, Sunstein hace un análisis detallado de los factores que dificultan una perfecta toma de decisiones por parte de los individuos. Basándose en el marco teórico propuesto por Daniel Kahneman en su libro Pensar rápido, pensar despacio (Kahneman 2012), Sunstein se centra en cuatro de los sesgos más destacados (págs. 8-18): incapacidad para predecir la adaptación a circunstancias futuras (sesgo de proyección); evaluación errónea de experiencias pasadas (sesgo de reminiscencia); inválidas proyecciones de estados mentales presentes en futuros inciertos (sesgo del presente); e incapacidad para extraer el rol de los efectos contextuales durante la toma de decisiones (sesgo contextual). Este conjunto de sesgos lleva a los seres humanos a comprometer la maximización de su bienestar. Si a esto le añadimos amplias asimetrías de información en la elección de bienes o servicios excesivamente complejos, como pueden ser los productos financieros, podemos llegar a la conclusión de que los seres humanos no somos tan racionales como la eco-

1 Salvo que se indique expresamente lo contrario, las citas incluidas en esta reseña provienen del libro de Sunstein. 
GAPP. Nueva Época - N. 25, marzo 2021 - ISSN: 1989-8991 - DOI: https://doi.org/10.24965/gapp.i25.10904 - [Págs. 87-90] Número monográfico - Los nudges y el diseño conductual de políticas públicas

Sunstein, Cass R.: Behavioral Science and Public Policy

Guillermo Kreiman

nomía neoclásica predice. Ciertas ramas de la psicología evolutiva y la biología conductual han ligado estos sesgos a cuestiones genéticas. Se podría resumir en lo que argumenta el profesor de Harvard y rockstar de la psicología experimental, Steven Pinker, en su famoso libro La Tabla Rasa: «A menudo las personas tienen deseos que subvierten su bienestar próximo [...] Estos impulsos personalmente desconcertantes tienen una lógica evolutiva transparente, e indican que la mente está llena de antojos configurados por la selección natural, y no de un deseo genérico de bienestar personal» (Pinker 2003, 95-96).

Una vez llegados a este punto, la cuestión que se plantea es inevitablemente la siguiente: si las personas, debido a falta de información o a los sesgos del comportamiento, son incapaces de conseguir aquello que maximice sus preferencias o su bienestar, ¿está justificada la intervención gubernamental para facilitarlo? Como argumenta Sunstein, «si la gente no sabe cómo llegar a donde quieren ir, un nudge puede ayudar» (pág. 7). Esta cuestión es la que abre la tercera parte del libro y plantea un profundo debate filosófico acerca de la necesidad de intervenir para resolver estos problemas. De esta manera, reabre nuevamente el antiguo debate tan enraizado en la filosofía política acerca del equilibrio entre la autonomía individual y el intervencionismo estatal.

El autor defiende, de manera implícita a lo largo del texto y de manera explícita en contadas ocasiones, que las entidades públicas deben intervenir a través de nudges para facilitar la maximización del bienestar de los ciudadanos en determinadas situaciones. Y esto se basa principalmente en que las instituciones públicas, a través de los descubrimientos de la ciencia, tienen tanto las herramientas como los conocimientos adecuados para estrechar la brecha entre comportamiento y bienestar. En palabras del autor: «Con respecto a cómo las elecciones afectarán realmente el bienestar, los observadores externos pueden saber mucho más, especialmente si el área requiere conocimientos técnicos» (pág. 42). Sin embargo, el autor es consciente del precario equilibrio existente entre libertad individual e intervencionismo estatal. Sunstein plantea cierta ambivalencia entre el deseo de mayor intervencionismo y la necesidad de mantener amplias esferas de autonomía a lo largo del libro. Algunos pasajes ciertamente ambiguos revelan las profundas tensiones normativas que subyacen a la aplicación de tales intervenciones. Como forma de encontrar ese equilibrio, Sunstein desarrolla una premisa teórica según la cual: «Cada uno de nosotros debe ser considerado por los outsiders como el mejor juez de nuestro propio bienestar, siempre que estemos adecuadamente informados y suficientemente libres de sesgos de comportamiento» (pág. 45). Es decir, las instituciones públicas podrán intervenir a través de nudges sólo en aquellas situaciones en las que existan asimetrías de información entre agentes, así como cuando concurran los anteriormente descritos sesgos de comportamiento. Limitando la esfera de actuación a estas situaciones, se busca reducir la aplicabilidad de estas intervenciones.

El libro de Sunstein resume de manera elegante y rigurosa los principales debates alrededor de este novedoso tipo de intervenciones. Sin embargo, me gustaría resaltar dos elementos que considero hubieran merecido un debate más profundo a lo largo del libro. Por una parte, en el plano normativo, tal y como reconoce el autor, el problema de los nudges es sumamente complejo y presenta numerosas ramificaciones. Dos cuestiones son dignas de mayor debate. En primer lugar, la presunción de que agentes externos, como los gobiernos, puedan llegar a poseer un conocimiento preciso de las preferencias de los ciudadanos. Es indudable que el avance científico en el campo de la ciencia del comportamiento no deja más lugar que reconocer la inaplicabilidad del mantra racionalista en la toma de un amplio abanico de decisiones. Sin embargo, el hecho de tener suficiente evidencia de las constantes tomas de decisiones erróneas por parte de los ciudadanos no implica que un agente externo, como las instituciones públicas, necesariamente posea un conocimiento lo suficientemente detallado de cuáles son las preferencias intrínsecas de los mismos. Un argumento de este tipo solo es capaz de sostenerse en marcos conceptuales que son incapaces de capturar el dinamismo, la fluidez y la naturaleza constantemente cambiante de las preferencias humanas. Incluso como describe el propio Sunstein, las preferencias pueden ser endógenas a las normas e instituciones existentes, reconociendo así un panorama mucho más complejo del que los argumentos teóricos del libro presuponen.

En segundo lugar, cabe resaltar la extremada amplitud de la principal premisa teórica presentada por Sunstein. Recordemos que, de acuerdo con ella, el autor establece que las instituciones solo podrán intervenir en el caso de que los individuos puedan actuar de manera racional debido a poseer la necesaria información y a no incurrir en sesgos de comportamiento. La excesiva laxitud de dicha premisa presenta cuestiones de difícil respuesta: ¿quién posee la capacidad suficiente para determinar que una decisión está siendo tomada de manera irracional? ¿Qué nivel de información es requerido para estar adecuadamente informados? ¿Cómo determina un observador externo las preferencias reales de los ciudadanos? En directa relación con ello, se plantea la problemática de potenciales aplicaciones excesivamente extensivas de esta premisa, pudiendo facilitar el desarrollo de numerosas políticas que no se circunscriban estrictamente a la 
GAPP. Nueva Época - N. 25, marzo 2021 - ISSN: 1989-8991 - DOI: https://doi.org/10.24965/gapp.i25.10904 - [Págs. 87-90] Número monográfico - Los nudges y el diseño conductual de políticas públicas

Sunstein, Cass R.: Behavioral Science and Public Policy

Guillermo Kreiman

búsqueda de la maximización del bienestar de los ciudadanos. Por ello, el uso de nudges parece recomendable para situaciones muy demarcadas, especialmente para aquellas con un impacto social directo o que presenten excesiva complejidad, como pueden ser cuestiones de salud pública, cambio climático, recaudación de impuestos o contratación de servicios financieros. Ampliar el uso de nudges a numerosos ámbitos puede llevar a resultados que van más allá de los deseables. En resumen, el problema de fondo es quién y cómo se determina la aplicabilidad de la premisa presentada por Sunstein. Por suerte, la complejidad de estas cuestiones no hace más que dotar de riqueza y amplitud el amplio debate académico que los nudges merecen.

En términos prácticos, dos elementos merecen mayor detenimiento. En primer lugar, cabría resaltar la aún naciente literatura sobre la efectividad de este tipo de intervenciones, lo que ha impedido un conocimiento más profundo de los efectos de las mismas. La elaboración sistemática de análisis científicos sobre los efectos concretos en una variedad lo suficientemente amplia de contextos dará robustez a la creciente evidencia empírica en este campo. A su vez, a pesar de constituir una categoría analítica concreta, existe una gran heterogeneidad entre los diversos tipos de nudges existentes. Sunstein se enfoca principalmente en cuatro: reglas por defecto; provisión de información (disclosure); prominencia (salience); y normas sociales (págs. 24-36). Un análisis desagregado de los efectos de cada una de estas intervenciones enriquecerá el debate sobre su efectividad, ya que ni todos los nudges son iguales, ni todos producen las mismas problemáticas.

En segundo lugar, es cuestionable la falta de reconocimiento de las limitaciones inherentes a cualquier tipo de estudio de carácter experimental. La gran mayoría de la evidencia en la que se basan los estudios sobre nudges son experimentos. A pesar de que este tipo de metodología es la más cercana al ideal experimental de las ciencias puras, incluso los estudios científicos de este tipo presentan numerosos sesgos y limitaciones, especialmente debido al bajo nivel de validez externa que presentan estos análisis. En cierta manera, el principal mérito de estos estudios reside en su capacidad de describir patrones de comportamiento que escapan de la esperable racionalidad, pero cabe preguntarse si son elementos suficientes como para determinar cuestiones tan complejas y en constante cambio como el de un conocimiento realmente informado sobre el bienestar de las personas.

Los nudges son una herramienta de un enorme atractivo debido a su carácter poco intrusivo y a la capacidad del individuo de mantener su propia libertad de elección. A diferencia de otras intervenciones, como las prohibiciones o los mandatos, no impone sanciones, sino que simplemente facilitan la toma de decisiones cuando el individuo carece de la capacidad suficiente para poder alcanzar la preferencia que desea. Este pequeño libro de Cass Sunstein es una introducción fantástica al complejo mundo de la ciencia del comportamiento, y más concretamente, al análisis de los nudges. No solo sienta las bases analíticas y conceptuales de este novedoso tipo de intervenciones, sino que recorre los principales descubrimientos en materia de ciencia del comportamiento y abre profundos debates desde un punto de vista normativo. $Y$ todo en tan solo 60 páginas. Por todo ello, Behavioral Science and Public Policy se convertirá en un libro de referencia para todos aquellos interesados en los nuevos avances en psicología cognitiva, psicología social y economía del comportamiento.

\section{REFERENCIAS BIBLIOGRÁFICAS}

Thaler, R. H. y Sunstein, C. R. (2009). Nudge: Improving decisions about health, wealth, and happiness. Penguin. Pinker, S. (2003). La Tabla Rasa. Editorial Paidós.

Kahneman, D. (2012). Pensar rápido, pensar despacio. Debate. 